\title{
Cold forging of gear components by a modified Samanta process
}

\author{
Conference Proceedings
}

\author{
A. Weiß ${ }^{1} \cdot$ T. Deliktas $^{1} \cdot$ M. Liewald ${ }^{1} \cdot$ N. Missal ${ }^{1}$ \\ Received: 29 April 2019 / Published online: 16 June 2020 \\ (c) The Author(s) 2020
}

\begin{abstract}
Cold forging of toothed components by extrusion is associated with high punching forces and tool loads, which requires the use of expensive and high-strength tool steels. High process forces result into a substantial tool deflection, which significantly reduces the precision of the toothed components. Thus, the development of alternative processes in order to reduce acting process forces in cold forging is of high interest. A potential process enhancement approach is to use a preform operation where the resulting preform can be formed partwise either in the same or in a subsequent die. Preforms allow to systematically control the material flow in subsequent forming operations. For this reason, the Institute for Metal Forming Technology in Stuttgart has developed a new cold extrusion process for manufacturing toothed components based on the conventional Samanta process. The newly developed die design of the Guided Material Flow—Samanta (GMF-Samanta) process enables efficient cold forging of gears. By means of numerical simulations and forging experiments it was successfully demonstrated that the new Guided Material Flow-Samanta process results into a significant reduction of punch force and normal pressure while simultaneously improving the die filling.
\end{abstract}

\section{Kaltfließpressen verzahnter Komponenten in einem modifizierten Samanta-Verfahren}

Konferenzbericht

\section{Zusammenfassung}

Das Kaltfließpressen verzahnter Komponenten ist mit hohen Stempelkräften und Werkzeugbelastungen verbunden, wodurch der Einsatz kostenintensiver und hochfester Werkzeugstähle erforderlich ist. Hohe Prozesskräfte führen zudem zu einer erheblichen elastischen Werkzeugdeformationen, welche die Form- und Maßgenauiugkeit der verzahnten Komponenten signifikant vermindert. Daher ist die Entwicklung alternativer Verfahren zur Reduktion der wirkenden Prozesskräfte in der Kaltmassivumformung von hohem Interesse. Ein möglicher Ansatz zur Prozessverbesserung ist die Anwendung einer Vorformoperation, bei der die resultierende Vorform am Werkstück entweder im gleichen oder in einem nachfolgenden Werkzeug weiter umgeformt werden kann. Vorformen ermöglichen es, den Materialfluss in der nachfolgenden Umformoperationen systematisch zu steuern und damit eine gezielte Reduktion der Reibfläche zwischen Werkstück und Werkzeug herbeizuführen. Aus diesem Grund hat das Institut für Umformtechnik in Stuttgart ein neues Kaltfließpressverfahren zur Herstellung von verzahnten Bauteilen entwickelt, das auf dem konventionellen Samanta-Prozess basiert. Die neuartige Fließpressmatrize des Guided Material Flow - Samanta (GMF - Samanta)-Verfahrens ermöglicht ein effizientes Kaltfließpressen von Verzahnungen. Mittels numerischer Simulationen und experimentellen Umformversuchen konnte erfolgreich nachgewiesen werden, dass das neue Guided Material Flow - Samanta-Verfahren zu einer signifikanten Reduktion der Stempelkraft und der Kontaktspannungen im Werkzeug bei gleichzeitiger Verbesserung der Formfüllung führt.

A. Weiß

andre.weiss@ifu.uni-stuttgart.de

1 Institute for Metal Forming Technology, University of Stuttgart, Stuttgart, Germany

\section{State of the Art}

Cold forging of toothed components is until today a technological challenge because narrow die cavities have to be filled with a high degree of precision. Preforming is used 
Fig. 1 a Basic process setup for the conventional Samanta process [9] and $\mathbf{b}$ the resulting high notch stress levels [6]

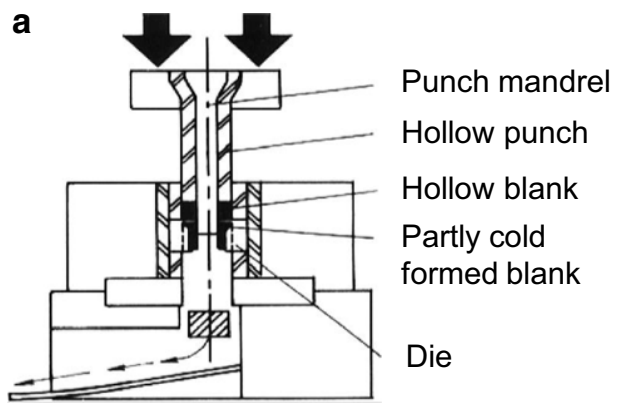

b

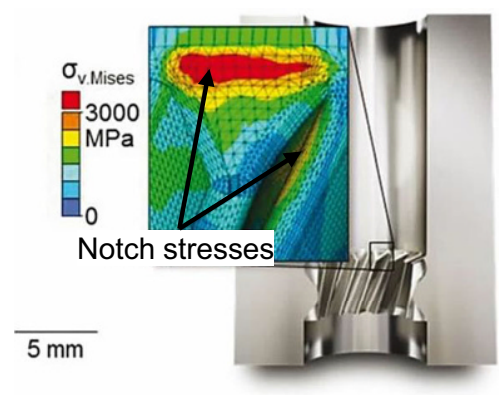

in hot forging, such as drop forging and precision forging, to improve die filling. Material pre-distribution is designed to ensure uniform and completely filled die cavities. Many studies have made use of the potential benefits of preforming, such as J.M. Monaghan [1], H. Ike [2] and P. Sieczkarek [3]. These studies have shown that improved die filling, a decrease in die load and punch forces can be accomplished by the use of a preform. Extrusion processes have become very important in the industrial production of gear components. Main reason for this can be found in simple design of the tools and the straight forward process in which a blank is pressed axially through an internally toothed die with adapted inlet geometry. In the forward extrusion of gearings the deformation takes places merely around the teeth [4]. The best known application of full forward extrusion and hollow forward extrusion for gear manufacturing is the Samanta process [5]. In the Samanta process, the blanks are pushed through the die one by one, using the subsequent blank to transmit the punch force (Fig. 1a). Disadvantages of the Samanta process are high notch stresses in the forming zone and gear inaccuracies (Fig. 1b; [6]). In order to overcome these disadvantages, the conventional Samanta process was optimized at the Institute for Metal Forming Technology in Stuttgart by an innovative die design $[7,8]$.

\section{Motivation and basic concept}

As can be concluded from the state of the art, the high normal pressures arising in the conventional Samanta process result in high die stresses, which also lead to high elastic die deflection, increased wear and process costs. In order to counteract these disadvantages, a new method was developed.

The fundamental concept of the new method is based on two enhancements, which are mutually dependent. The first enhancement is achieved by forming the teeth gradually in a longer distance, rather than an abrupt forming as in the conventional Samanta process. In this approach, the tooth head is completely formed before the tooth root preventing the possible underfilling of the tooth head. This en- hancement ensures a complete filling of the teeth form. The gradual forming approach reduces also the contact pressure peaks and yields rather evenly distributed normal pressures. Throughout such a gradual forming process, large friction surfaces and increased punch forces are expected. The second approach counteracts this problem of large friction surfaces by introducing a die undercut and thereby contact release to prevent stress peaks. Using these two ideas, a novel die design has been developed which will be explained in the following.

\section{Guided Material Flow-Samanta process}

The proposed Guided Material Flow-Samanta (GMFSamanta) process can be applied identical to form solid and hollow blanks. As explained in the previous section, the innovation is realized by a special die design, which creates a preform toothing on the blanks through a controlled material flow in the early phase of the process. This first modification of successive forming causes a reduction of the die load and subsequently a decreased die stress. Successive forming is realized by dividing the complete forming of the tooth profile into two sections of the die where different parts of the tooth are formed successively. A major distinction is made between these two sections, namely the preform section and the calibration section as shown in Fig. 2a. In the preform section a pre-distribution of the material occurs. Whereas in the calibration section, the pressure increase forms the tooth profile completely.

Both sections are designed to have different die opening angles. The preform section has a die opening angle of $\alpha_{1}=10^{\circ}$ and the calibration section has a die opening angle of $\alpha_{2}=16.5^{\circ}$. The given die opening angles were obtained by iteratively optimizing the gear geometry used in this paper. The comparison in Fig. $2 b$ shows the differences between the die designs of the conventional Samanta process and the GMF-Samanta process.

In the conventional Samanta process, the forming of the gears is achieved in a short distance by a constant die opening angle by abruptly forming the teeth without utilizing 
Fig. 2 a Die cross-section of the GMF-Samanta process; b Comparison between the die of the conventional Samanta and GMF-Samanta process

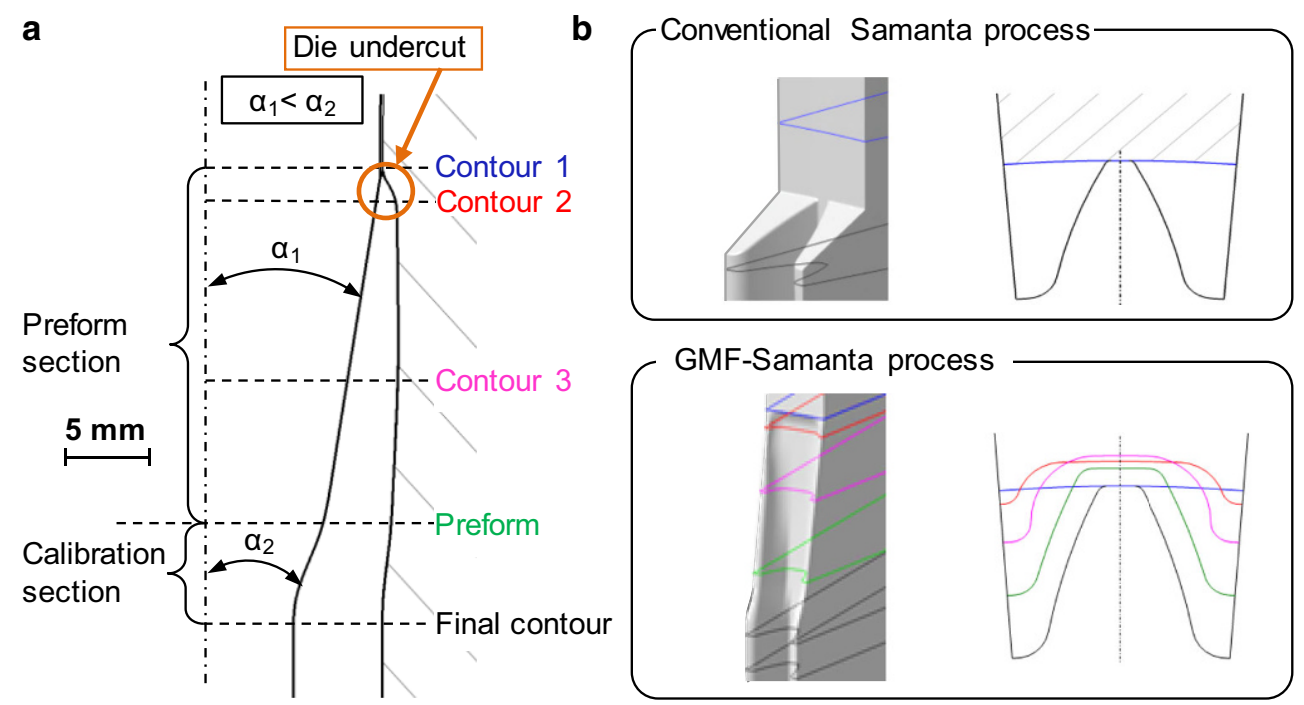

the concept of material pre-distribution. A deformation of the cylindrical "Contour 1" to the desired final contour in short distance results into high tool loads due to continuous frictional contact with the die at high normal pressure. In contrast, the modified GMF-Samanta process uses a variety of different preform contours to pre-distribute the blank material. These different preform die contours form the teeth gradually. It is designed to first preform the material in radial direction and thereby facilitating the forming to involute toothing. The geometry of the preform contour is very important in the optimization of the process parameters. Preform contours have been arranged in such a way that material is initially pre-distributed along the tooth root diameter (Contour 2 in Fig. 2a) starting from a circular geometry (Contour 1 in Fig. 2a). Subsequently, the tooth root diameter of the gearwheel is continuously reduced until the required value is attained (Contour 3 in Fig. 2a).

In order to ensure a complete die filling of the tooth head, the height of the tooth head is reduced from the "Preform contour" to the "Final contour". During this process phase, the root of the tooth is formed completely to the required depth. In general, the preform differs from the involute tooth contour by a larger pitch. The larger pitch serves to accumulate a larger amount of material in the radial direction, which is then used in the calibration section to completely form the gear. In addition, the preform is provided with larger radial inward and outward transitions to reduce the die stress. The larger radial transition also serves to reduce notch stresses in the die and also promotes the material flow in radial direction. By means of this die design a longer but advantageous forming path can be achieved in one process step.

The extended forming stroke explained above results in large friction surfaces. This should increase the process forces unless the contact normal pressures are reduced. In order to reduce the contact normal pressures and process forces the material is partly separated from the die in the forming zone using die undercuts. This reduces the friction surfaces and stress peaks. In the designed die an undercut in radial direction has been used with continuously changing contours. Thereby the material flow is radially guided outward and inwards between the initial blank diameter and the final tip diameter of the gear. In conventional Samanta processes the tooth is formed only inward since the tooth head diameter is always smaller than the initial workpiece diameter. Fig. 2a illustrates that the die undercut starts between "Contour 1" and "Contour 2". The die undercut extends up to "Preform contour". Between "Preform contour" and "Final contour" the undercut is reduced to the initial diameter calibrating the tooth head in the final stage. Material located at the tooth root reveals a complete contact with the die. At the tooth head, however, the material contacts the die only between "Preform contour" and "Final contour". Through radial expansion and compression of the material the normal pressures are reduced significantly.

\section{Simulation setup}

Due to the symmetry of the geometry the numerical study considers only one half of a tooth with consistent parameters. The investigated gearwheel has 40 teeth (z), the module $(\mathrm{m}) 2 \mathrm{~mm}$, base diameter $\left(\mathrm{d}_{\mathrm{b}}\right) 84.57 \mathrm{~mm}$, tooth root diameter $\left(\mathrm{d}_{\mathrm{tr}}\right) 85.08 \mathrm{~mm}$, outside diameter $\left(\mathrm{d}_{\mathrm{o}}\right) 95.35 \mathrm{~mm}$ and a pitch diameter (d) $90.00 \mathrm{~mm}$. This gear wheel geometry is based on the project "massiverLeichtbau" and was also used by Meißner [8]. 
Fig. 3 Contact area between workpiece and die a conventional Samanta process b GMF-Samanta process
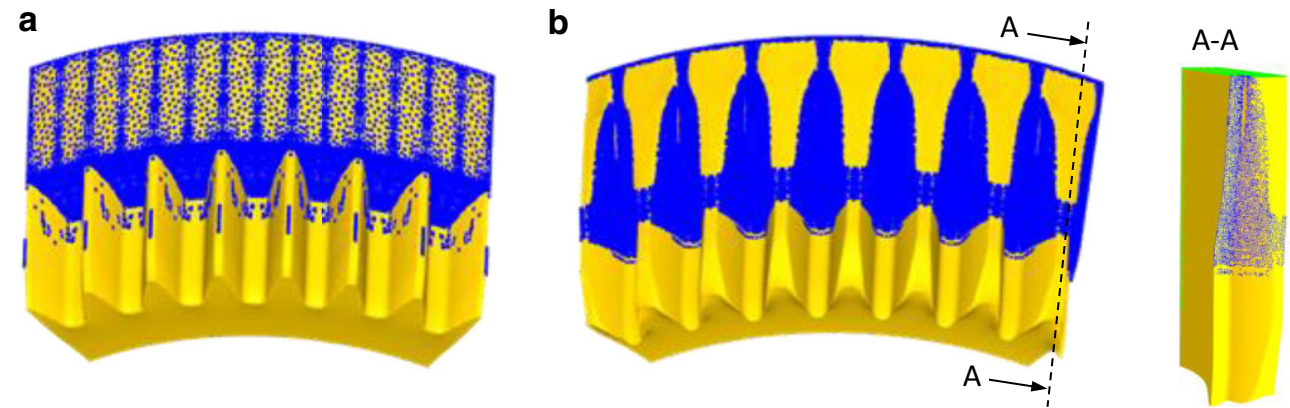

a

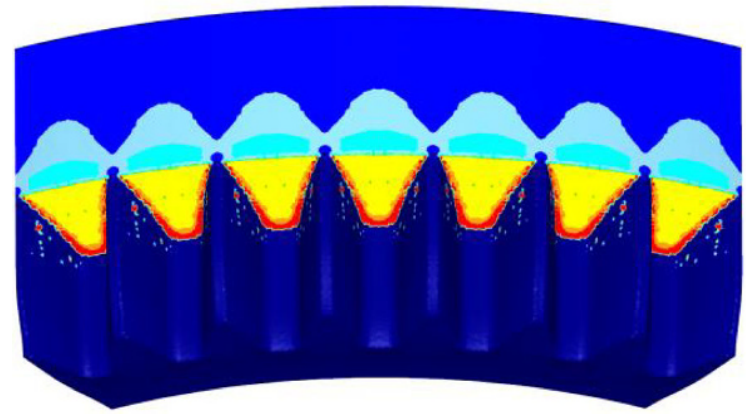

b

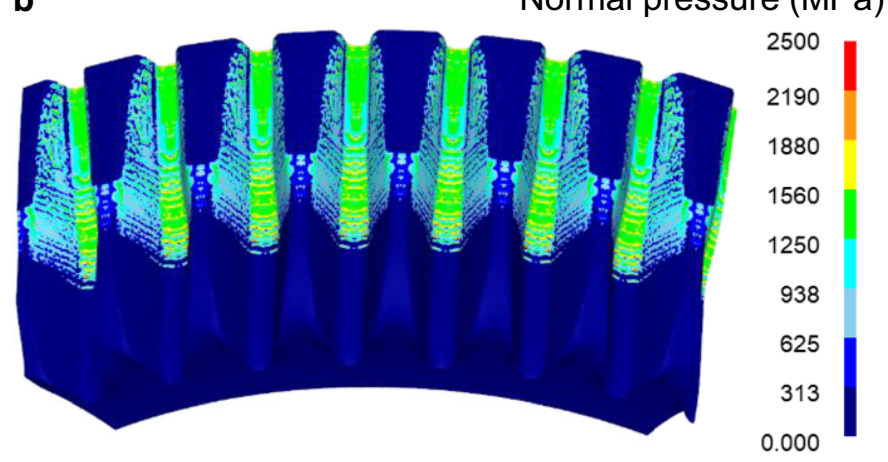

Fig. 4 Comparison of the normal pressure a Conventional Samanta process b GMF-Samanta process

The GMF-Samanta process was iteratively optimized by successive numerical simulations using Deform $3 \mathrm{D}^{\mathrm{TM}}$. In the simulation, a hollow forward extrusion process was modelled to reduce computational demands. A punch with a mandrel was used in the forming process, as illustrated in Fig. 1a. The diameter of the mandrel and consequently the inside diameter of the formed gearwheel is $70 \mathrm{~mm}$. Tools have been modelled as rigid in the first approach. The hollow workpiece made of $\mathrm{C} 4 \mathrm{C}$ material was modelled as rigid-plastic. For this simulation a tetrahedral mesh with an amount of 160,000 elements for the workpiece and a minimum element size of $0.08 \mathrm{~mm}$ was selected. The flow curves of the $\mathrm{C} 4 \mathrm{C}$ material were measured by compression tests on a Gleeble 3800c and were implemented in Deform 3D ${ }^{\mathrm{TM}}$. The thermomechanical forming process was simulated with an initial workpiece temperature of $20^{\circ} \mathrm{C}$. Coulomb friction model was selected with a coefficient of 0.07. A constant ram speed of $50 \mathrm{~mm} / \mathrm{s}$ was used. The GMF process was simulated with a single workpiece that was completely pressed through the die without loading another workpiece. This simplification led to a reduction of calculation time and doesn't affect the evaluation of the die filling, the maximum punch force and the contact pressure. For comparison of the GMF process with a conventional Samanta process simulations of a conventional Samanta process with three different die opening angles were conducted and evaluated using the same simulation settings.

\section{Evaluation of simulation results}

To compare calculated differences between the innovative GMF-Samanta process and the conventional Samanta process, an identical gear was simulated also with a conventional die. In the following, the two processes are compared based on the die filling, normal pressures, equivalent stress distributions and required punch forces. Die filling can be identified on the basis of the contact area between the workpiece and the die, which are represented in Deform $3 \mathrm{D}^{\mathrm{TM}}$ as contact nodes. Fig. 3 shows a comparison of the obtained contact areas between workpiece and tool in the conventional Samanta process and GMF-Samanta process. The conventional Samanta process in Fig. 3a disclose distributed and broader contact between workpiece and tool in the area of the extrusion shoulder and the blank guidance can be noticed. The large die opening angle of the extrusion shoulders and the high normal pressure results into high punch forces. Fig. 3b illustrates the die-undercut which results into material separation in the preform section. The undercut in the die enables an extension of the punch stroke while the friction surface remains constant. Also noticeable for the first workpiece shown in Fig. $3 \mathrm{~b}$ is the crown-shaped deformation on the bottom of the workpiece and the underfilling in the initial area of the gearing.

In the GMF-Samanta process, the successive forming of toothing results into an extended punch stroke. An extended punch stroke without increased punch force can only 
a

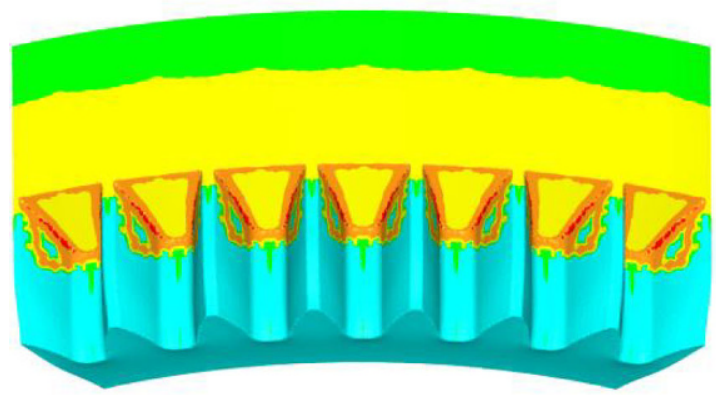

b

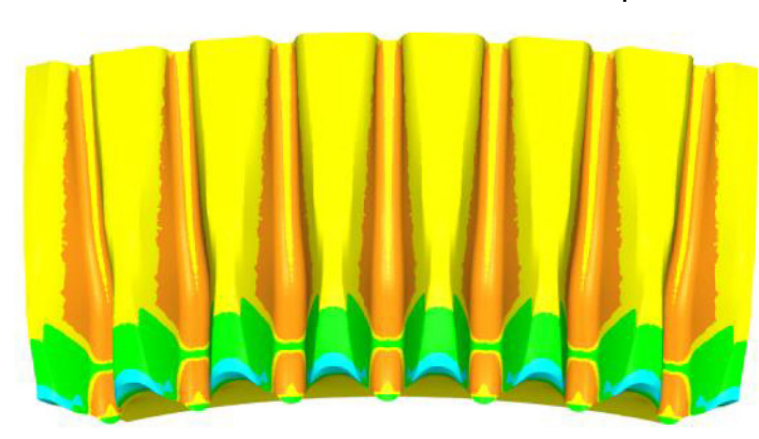

Equivalent stress (MPa)

1200

925

650

375

100

$-175$

$-450$

$-725$

$-1000$

Fig. 5 Comparison of equivalent stress on workpiece a conventional Samanta process b GMF-Samanta process

Fig. 6 Illustration of numerically calculated force-stroke curves of the different Samanta processes (workpiece material: C4C/1.0303)

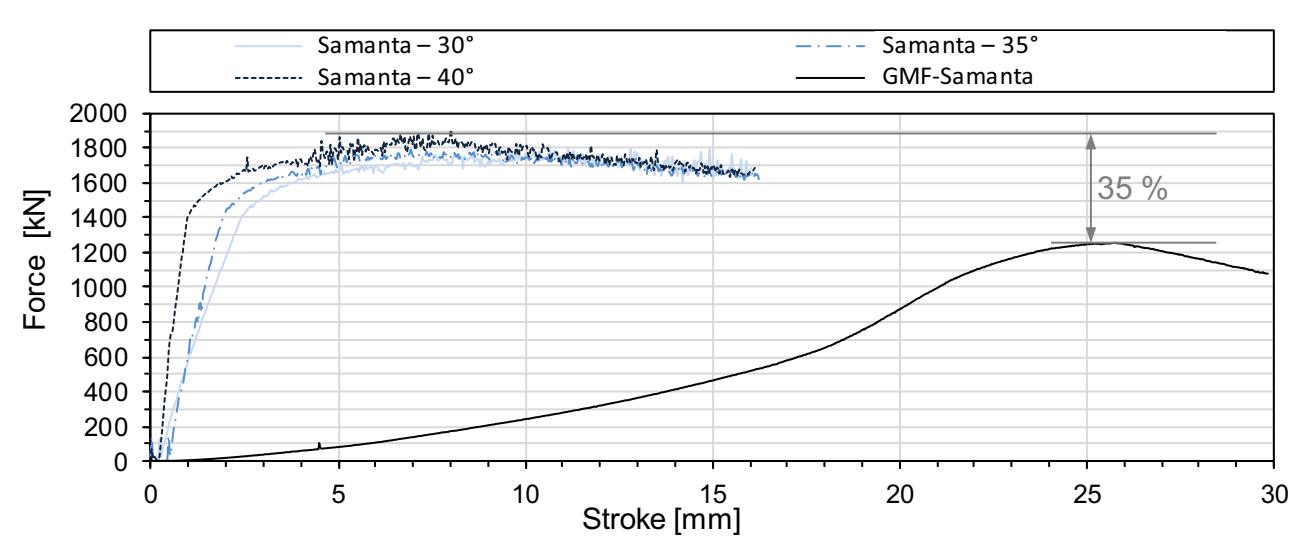

be achieved by reducing the friction surface and the amount of contact pressures between workpiece and die. These parameter characteristics are typical for performing Samanta processes, as this technology is performed without a counter punch.

A comparison of emerging normal pressure between the both processes is given in Fig. 4. Fig. $4 \mathrm{~b}$ shows the normal pressure of the die in the GMF-Samanta process. The highest normal pressure values occur in the area where the forming of the tooth root diameter of the gear wheel is performed. In this area, surface pressures between 1500-1900 MPa occur. In the conventional Samanta process significantly higher amount of normal pressure develops. Fig. 4a shows a normal pressure of over $2500 \mathrm{MPa}$ in the area of the extrusion shoulder. Due to high normal pressure in the conventional Samanta process, for that reason increased tool wear and reduced gear precision is expected.

The calculated distributions of equivalent stress values on the workpiece can be used to predict surface defects and potential cracks. A comparison of the equivalent stresses during the conventional Samanta process and the GMFSamanta process is shown in Fig. 5. In the conventional Samanta process, high tensile stresses occur in the area of the extrusion shoulder, which reach a maximum of
$1200 \mathrm{MPa}$. In addition, high local stress differences occur in the area of the extrusion shoulder (Fig. 5a). The GMFSamanta process in Fig. 5b shows lower tensile stresses. Thereby a maximum tensile stress of $800 \mathrm{MPa}$ and generally lower local stress differences can be observed. In order to reduce the stresses occurring in the workpiece, the radius between the tooth root circle and the tooth flank were varied during the tool design optimization. These geometry features have a significant influence on the amount of the radial material flow. A larger transition radius leads to a higher amount of material being pressed into radial direction, whereas a smaller radius inhibits the material flow from being pressed in the radial direction.

A comparison of the computed force-stroke curves for the GMF-Samanta process and for the conventional Samanta process with three different die opening angles is illustrated in Fig. 6. In the conventional Samanta process, the maximum punch force is rather insensitive to the die opening angle. The maximum punch force significantly do increase as the die opening angle increases. With the three die opening angles $30^{\circ}, 35^{\circ}$ and $40^{\circ}$, the corresponding maximum punch forces are between 1700 and $1900 \mathrm{kN}$. Whereby the total deformation work is applied on the workpiece within a short stroke. In contrast, in the GMF- 
Fig. 7 a Design of the experimental forging tool b Surface finish of the additively manufactured die after abrasive flow machining
Fig. 8 Experimental and numerical results a Punch force-stroke curves of $16 \mathrm{MnCr} 5, \mathrm{C} 4 \mathrm{C}$ and EN AW 1050 b Gear made of C4C a

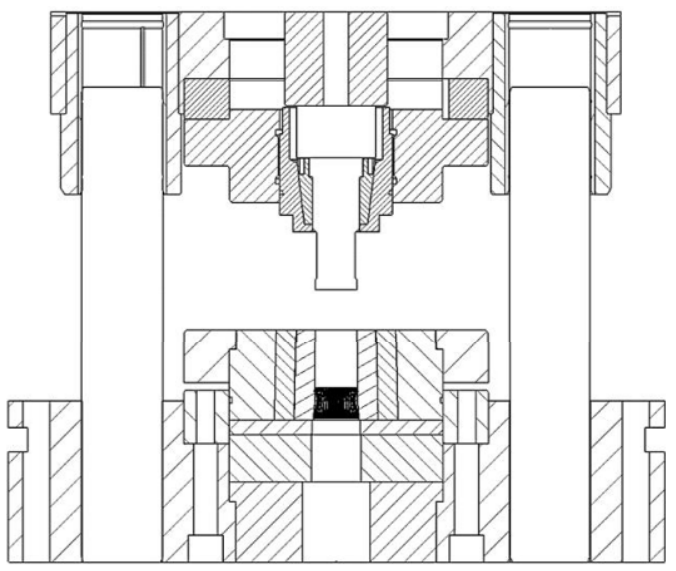

b

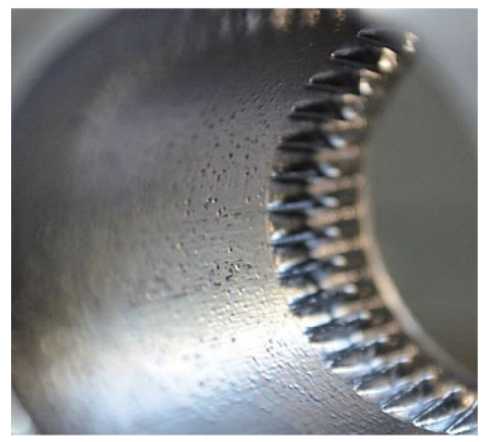

a

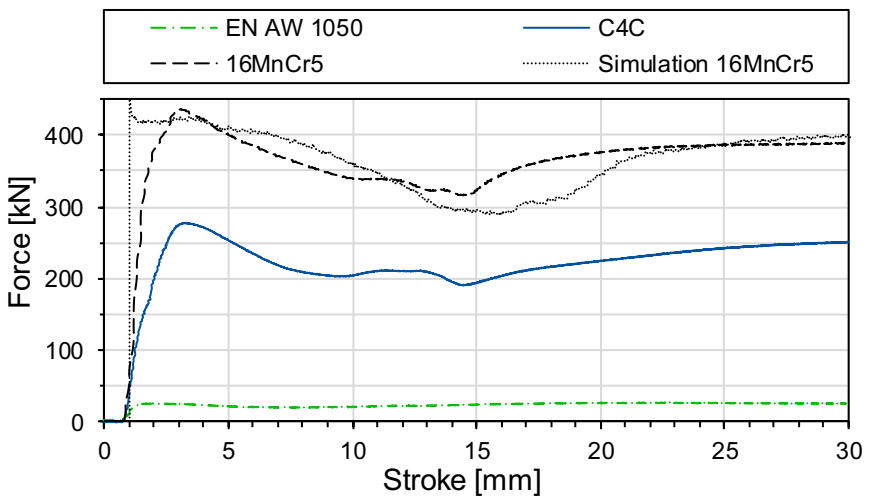

b

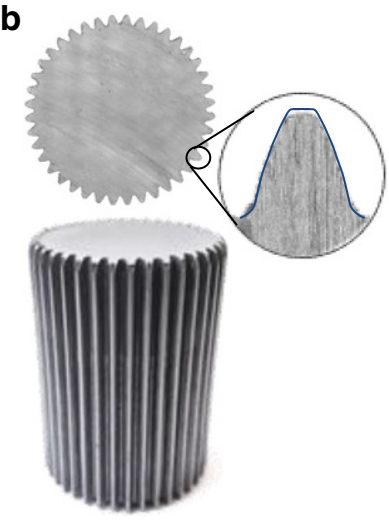

Samanta process, the total deformation work is applied over a considerably longer punch stroke. At a stroke of approximately $18 \mathrm{~mm}$, the workpiece reaches the "Preform contour" and the die opening angle $\alpha_{2}$ of the calibration section leads to an increase in punch force. At a stroke of $25 \mathrm{~mm}$, the GMF-Samanta process reaches its maximum punch force of $1250 \mathrm{kN}$ and decreases afterwards gradually due to reducing area of contact until the part is completely pressed through the die. The distribution of the total deformation work along a larger punch stroke results into a reduction of by $35 \%$ compared to the conventional Samanta process.

\section{Evaluation of experimental results}

In order to conduct forging experiments in the laboratory scale, the die of the GMF-Samanta process was manufactured on a scale of 1:3. Scaling was necessary to demonstrate the general viability of the process with already existing tool racks. Due to the complex die geometry, the die was manufactured using an additive manufacturing process by selective laser melting of 1.2709 tool steel. Outer sur- faces of the die have been grinded and the inner surface has been reworked by abrasive flow machining. The requirement on the average roughness ( $\mathrm{Ra} 0.4$ ) was achieved on the grinded surfaces, whereas the surface finish performed by abrasive flow machining showed large pores (Fig. 7b).

It is expected that the surface roughness will increase the friction considerably. The additively manufactured die was press-fitted into a double shrink ring and installed into the experimental tool shown in Fig. 7a. As the feasibility of the process and the die filling at the toothing were selected as the most important evaluation criteria, the process was carried out as full forward extrusion. All tests in this framework of this paper were performed on the Schuler servo-mechanical press type MSL 1-500-0.85-500. The first blank was inserted into the die and pressed through the die. Then, the first blank in the die was pushed through by the following blank. The first forging tests were carried out with the aluminum alloy EN AW 1050 for safety reasons. Then blanks made of $\mathrm{C} 4 \mathrm{C}$ and $16 \mathrm{MnCr} 5$ were also formed. All blanks (diameter $31.5 \mathrm{~mm}$, height $35 \mathrm{~mm}$ ) were coated with the lubricant "Beruforge 120D". The feasibility of the process was verified by the experimental tool design. The additive manufactured die in the newly developed Samanta 
process was successfully used for the forming of a gear made of aluminium and steel. Fig. 8b shows a cold forged part made of $\mathrm{C} 4 \mathrm{C}$ formed using the GMF-Samanta process. A complete die filling of the toothing could be achieved for all three materials tested in this study. As a result of the dimensional deviations of the additive manufactured die, all workpieces deviated from the ideal geometry by a maximum of $0.14 \mathrm{~mm}$ (blue line indicates ideal geometry). Therefore, a conventional manufactured die will be used in future work. The force-stroke curves of the different materials recorded during the test are shown in Fig. 8a.

These curves were recorded when forming the second blank. In Samanta processes, the force-stroke curve characteristics of the first workpiece differ from those of the second workpiece while maximum force is identical for both workpieces. The numerical investigations in Sect. 5 only examined the first workpiece. For comparison, a simulation of the second workpiece was carried out with the geometries used in experiment. The friction coefficient had to be increased in order to reach similar poor friction conditions as in the experiments. Due to the ideal plastic simulation, the simulation initially deviates from the experimental investigations. Considering the force-stroke curve characteristics, a good correlation of simulation and experimental results could be achieved. The major aim of this experimental study was to verify the feasibility of the process and the application of additive manufactured tools for cold forging processes.

\section{Summary}

In this study, a new cold forging process was developed and numerically investigated for cold forging of gear shapes and gear wheels based on established Samanta process. Objective of the investigation was to verify the feasibility of the process and to compare the numerical results with the conventional Samanta process sequence. In addition, the feasibility of the process was demonstrated experimentally using a downscaled die. The newly developed GMF-Samanta process offers many advantages compared to the conventional Samanta process due to its controlled material flow. Through the successive forming sequence, the punch force was remarkle reduced by approximately $35 \%$ compared to the conventional Samanta process. The equivalent stresses applied on the workpiece also were decreased by a factor of one third, which considerably reduces the risk of work- piece damages. In addition, the normal pressure on the die surface has been significantly reduced, which is expected to increase the tool lifetime. The advantages of the new process were achieved by gradually forming the tooth profile and a reduction of the friction surface by using undercuts in the die design. When reducing the die load, the use of additive manufacturing methods has become practicable for tool components in cold forging. The additively manufactured die insert was integrated into an experimental tool. The experimental tool was successfully used for cold forging three different materials (16MnCr5, C4C, EN AW 1050).

Funding Open Access funding provided by Projekt DEAL.

Open Access This article is licensed under a Creative Commons Attribution 4.0 International License, which permits use, sharing, adaptation, distribution and reproduction in any medium or format, as long as you give appropriate credit to the original author(s) and the source, provide a link to the Creative Commons licence, and indicate if changes were made. The images or other third party material in this article are included in the article's Creative Commons licence, unless indicated otherwise in a credit line to the material. If material is not included in the article's Creative Commons licence and your intended use is not permitted by statutory regulation or exceeds the permitted use, you will need to obtain permission directly from the copyright holder. To view a copy of this licence, visit http://creativecommons.org/licenses/by/4. $0 /$.

\section{References}

1. Monaghan JM (1988) An upper-bound analysis of an axisymmetrical coining process. J Mech Work Technol 16:175-192

2. Ike H (2003) Surface deformation vs . bulk plastic deformation-a key for microscopic control of surfaces in metal forming. J Mater Process Technol 138:250-255

3. Sieczkarek P, Wernicke S, Gies S, Tekkaya AE (2017) Improvement strategies for the formfilling in incremental gear forming processes. Prod Eng 11(6):623-631

4. Lennartz J (1994) Kaltfließpressen von gerad- und schrägverzahnten Getriebewellen. Fortschrittberichte VDI, vol 341. RheinischWestfälische Technische Hochschule Aachen, Aachen

5. Samanta SK (1975) Apparatus and method for cold extrusion of gears. US Patent No. 3910091

6. Kiener C, Merklein M (2017) Virtuelle Analysetools - Eine smarte Methode zur effizienten Erforschung von Kaltfließpressprozessen. Z Konstr 11-12:78-82

7. Weiß A et al (2018) Manufacture of face gearing - a new production method by means of determined material pre-distribution. 17th Int. Conf. Met. Form, pp 511-518

8. Meissner R et al (2019) Novel approach in cold forging for efficient manufacturing of shaft-hub-assemblies. ESAFORM Conference on Material Forming, Vitoria-Gasteiz

9. Lange K, Kammerer M (2008) Fließpressen. Springer, Heidelberg, Berlin, New York 